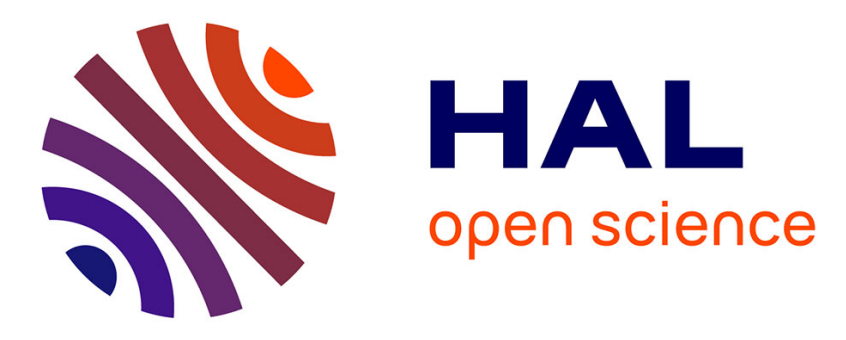

\title{
Ultraviolet, Infrared, and High-Low Energy Photodissociation of Post-Translationally Modified Peptides
}

Mohammad Halim, Luke Macaleese, Jérôme Lemoine, Rodolphe Antoine, Philippe Dugourd, Marion Girod

\section{To cite this version:}

Mohammad Halim, Luke Macaleese, Jérôme Lemoine, Rodolphe Antoine, Philippe Dugourd, et al.. Ultraviolet, Infrared, and High-Low Energy Photodissociation of Post-Translationally Modified Peptides. Journal of The American Society for Mass Spectrometry, 2018, 29 (2), pp.270 - 283. 10.1007/s13361017-1794-9 . hal-01767664

\section{HAL Id: hal-01767664 https://hal.science/hal-01767664}

Submitted on 7 Sep 2020

HAL is a multi-disciplinary open access archive for the deposit and dissemination of scientific research documents, whether they are published or not. The documents may come from teaching and research institutions in France or abroad, or from public or private research centers.
L'archive ouverte pluridisciplinaire HAL, est destinée au dépôt et à la diffusion de documents scientifiques de niveau recherche, publiés ou non, émanant des établissements d'enseignement et de recherche français ou étrangers, des laboratoires publics ou privés. 


\section{Ultraviolet, Infrared and High-Low Energy Photodissociation of Post-Translationally Modified Peptides}

Mohammad A. Halim, ${ }^{1}$ Luke MacAleese, ${ }^{1}$ Jérôme Lemoine, ${ }^{2}$ Rodolphe Antoine, ${ }^{1}$ Philippe Dugourd, ${ }^{1}$ Marion Girod ${ }^{2}$

${ }^{1}$ Univ Lyon, Université Claude Bernard Lyon 1, CNRS, Institut Lumière Matière, F-69622, LYON, France

${ }^{2}$ Université de Lyon, Institut des Sciences Analytiques, UMR 5280, CNRS, Université Lyon 1, ENS Lyon, 69622 Villeurbanne Cedex, France

Correspondance to: Philippe Dugourd, Email: philippe.dugourd@univ-lyon1.fr 


\begin{abstract}
Mass spectrometry based methods have made significant progress in characterizing post-translational modifications in peptides and proteins; however, certain aspects regarding fragmentation methods must still be improved. A good technique is expected to provide excellent sequence information, locate PTM sites and retain the labile PTM groups. To address these issues, we investigate $10.6 \mu \mathrm{m}$ IRMPD, $213 \mathrm{~nm}$ UVPD and combined UV and IR photodissociation, known as HiLoPD (High-Low Photodissociation), for phospho-, sulfo- and glyco-peptide cations. IRMPD shows excellent backbone fragmentation and produces equal numbers of $\mathrm{N}$-and $\mathrm{C}$-terminal ions. The results reveal that $213 \mathrm{~nm}$ UVPD and HiLoPD methods can provide diverse backbone fragmentation producing $\mathrm{a} / \mathrm{x}, \mathrm{b} / \mathrm{y}$ and $\mathrm{c} / \mathrm{z}$ ions with excellent sequence coverage, locate PTM sites and offer reasonable retention efficiency for phospho- and glycol-peptides. Excellent sequence coverage is achieved for sulfo-peptides and the position of the $\mathrm{SO}_{3}$ group can be pinpointed; however, widespread $\mathrm{SO}_{3}$ losses are detected irrespective of the methods used herein. Based on the overall performance achieved, we believe that $213 \mathrm{~nm}$ UVPD and HiLoPD can serve as alternative options to collision activation and electron transfer dissociations for phospho- and glyco-proteomics.
\end{abstract}

Keywords: Photofragmentation, Post-transnational modifications, Fragmentation method, UVPD, IRMPD 


\section{Introduction}

The identification and mapping of post-translational modifications (PTMs) in peptides and proteins is challenging because of their low abundance, lability and unique chemical properties [1, 2]. Mass spectrometry based analysis of phosphorylation [3], sulfonation [4], and glycosylation [5] plays an important role in understanding their diverse biological functions. Phosphorylation by protein kinases regulates signal transduction for diverse intracellular processes [6, 7]. Many diseases such as cancer, inflammation, metabolic disorders, and neurodegenerative diseases are also linked to kinase protein phosphorylation [8]. The key functions of tyrosine sulfation are protein-protein interaction regulation, hormonal regulation and hemostasis $[9,10]$. It is difficult to characterize the sulfo-proteome due to its very acidic nature and labile sulfo-ester bond [11]. In glycoproteins, an oligosaccharide chain (glycan) is covalently attached to the polypeptide side-chain [12]. Glycosylation is associated with plasma-membrane and secretory proteins [13]. Moreover, proteins that have an extracellular segment are often glycosylated. Glycosylation has been linked with several human diseases such as inflammation [14], cancer [15], genetic disorders [16] and neurodegenerative disorders $[17,18]$. Glycoproteins are difficult to characterize due to the low-abundance, complexity and heterogeneity of glycan structures [19].

Tandem Mass Spectrometry (MS/MS) has emerged as an indispensable tool for analyzing the PTMs of proteins as it can provide structural information with high accuracy, relative speed and sensitivity [20,21]. Fragmentation methods are crucial to obtain precise structural information. Collision induced dissociation (CID) is frequently applied for fragmenting peptide ions. Although CID can recognize the presence of phosphate (especially from pSer and pThr) in a peptide or protein, by identifying the loss of a phosphate $\left(-80 \mathrm{HPO}_{3}\right.$ or $-98 \mathrm{H}_{3} \mathrm{PO}_{4}$ ) group from the precursor ion, identifying the exact site is a challenging problem [22]. The neutral loss of phosphate groups from tyrosine is not always observed due to the strong phosphate-tyrosine binding energy and lower abundance of pTyr phosphorylation compared to pSer and pThr [23, 24]. Moreover, as sulfonation $\left(\mathrm{SO}_{3}\right)$ and phosphorylation $\left(\mathrm{HPO}_{3}\right)$ both result in the loss of $80 \mathrm{Da}$ it makes PTM identification even more challenging. One inherent problem with CID is that the excitation of precursor ions requires increasing internal energy, which increases neutral loss and in turn provides limited structural information [22]. However, metastable atom-activated dissociation (MAD) and 
higher-energy collision dissociation (HCD) experiments on phosphorylated and sulfonated peptides in negative ion mode have led to significant improvements [25, 26]. Recently, using dual spray ion/ion reactions, traditional collision induced dissociation (CID) underwent significant improvement in terms of phosphate group fragmentation and retention [27].

Electron-driven methods based on 'ion-electron' activation in electron capture dissociation (ECD) [28] and 'ion-ion' activation in electron transfer dissociation (ETD) [29] have been developed as an alternative to CID. In ECD and ETD, low energy electrons $(\sim 1$ $\mathrm{eV}$ ) are captured (or transferred) by precursor ions [30]. After receiving an electron, the activated precursor ions specifically break the $\mathrm{N}-\mathrm{C}_{\alpha}$ bonds and yield $\mathrm{c}$ and $\mathrm{z}$ ions without abundant side-chain loss, making it possible to identify the locations of PTM sites [31, 32]. However, ECD and ETD methods require multiply charged ions, which is difficult to form for the acidic phosphate and sulfonate groups in PTMs [30, 33, 34]. Incorporating metal ions in phospho and sulfo sites can improve localization and fragmentation by generating multiple charge states $[35,36]$. Due to the acidic nature of phospho- and sulfo- groups in the PTM peptide, they can present improved ionization when negative polarity is used in ESI (Electrospray Ionization) and provide good fragmentation while retaining the PTM groups [37-39]. However, irrespective of activation methods peptide anions produce more complex MS/MS spectra caused by manifold fragmentation events with widespread side chain losses, making it difficult to process, interpret and analyze the resulting complex data-sets [40-45].

Alternatives to 'ion-ion' activation technique are also available, such as various UV photon-based methods including $157 \mathrm{~nm}$ [46], $193 \mathrm{~nm}$ [47-50], $220 \mathrm{~nm}$ [51], $266 \mathrm{~nm}$ [52] ultraviolet photodissociation (UVPD), and electron detachment dissociations (EDD) [53]. Kim et al observed series of a/x ions in $157 \mathrm{~nm}$ VUVPD on phospho-peptides and noticed the retention of the phosphate group [46]. They also found that phospho-tyrosine is more stable compared to phosphoserine or phosphothreonine. $193 \mathrm{~nm}$ UVPD with negative polarity is capable of providing interesting features, such as excellent sequence coverage and the retention of $\mathrm{H}_{3} \mathrm{PO}_{4}$ and $\mathrm{SO}_{3}$ groups from product ions of phospho- and sulfo- peptides [50, 54, 55]. $220 \mathrm{~nm}$ UVPD on protonated tyrosine containing phospho-peptides showed characteristic aromatic side chain losses of the tyrosine residue [51]. Aromatic side chain loss was also observed at $266 \mathrm{~nm}$ for electron detachment dissociation (EDD) for peptide anions [53]; however, this loss was suppressed for phospho-peptide cations [52]. Compared to high-energy UV photodissociation, few studies have been performed using $10.6 \mu \mathrm{m}$ infrared multiphoton dissociation (IRMPD) [56-59] for PTM characterization. Despite several challenges and 
difficulties, the potential of IRMPD is similar to certain other photoexcitation techniques [6062] since this method: i) requires no alternation of the stable trajectory or kinetic energy of the trapped ion for excitation; ii) is not associated with low cutoff $\mathrm{m} / \mathrm{z}$; iii) can provide reasonable fragmentation efficiency; iv) can operate without collision gas; v) and it is compatible with the vibrational modes of $\mathrm{PO}_{4}{ }^{3-}$ and $\mathrm{SO}_{3}$ groups present in PTMs.

Although various wavelengths between 157-266 nm were employed in ultraviolet photodissociation for characterizing post-translational modifications, $213 \mathrm{~nm}$ UVPD [41, 63] has never been used before for this purpose. A single high energy UV photon is sufficient to promote the dissociation of a peptide and protein, cleaving mainly $\mathrm{C} \alpha-\mathrm{C}$ bonds and producing abundant $\mathrm{a} / \mathrm{x}$ ions with some $\mathrm{y}$ and $\mathrm{z}$ ions. On the other hand, the multiple absorption of low energy IR photons is required to increase the internal energy and cleave the labile $\mathrm{C}-\mathrm{N}$ bonds, generating mainly $\mathrm{b} / \mathrm{y}$ ions. In general, the key advantages of coupling high and low energy photon-based activation are that they provide a balanced and diverse array of fragment ions and an even distribution of the fragment ions across the entire $m / z$ range. Although $213 \mathrm{~nm}$ UVPD and other methods (157 nm and $193 \mathrm{~nm}$ UVPD) provide large numbers of fragment ions, the latter are usually highly charged and are thus observed at $m / z$ very close to that of the precursor ion, hence crowding the MS/MS spectra. In this study, we employ a new method called HiLoPD (high-low photodissociation) [64], that combines high-energy UV and lowenergy IR lasers with a high resolution Q-Exactive mass spectrometer encompassing high and low photoactivation channels for PTM characterization. We also evaluate the performance of 10.6 $\mu \mathrm{m}$ IRMPD, $213 \mathrm{~nm}$ UVPD and HiLoPD for phospho-, sulfo- and glyco-peptide cation characterization in view to achieving three goals: i) obtain adequate backbone fragmentation with good sequence coverage; ii) identify the exact position of PTMs groups; and iii) compare the loss and retain events of the labile PTMs groups in the fragment ions.

\section{Materials and Methods}

\section{Sample Preparation}

Phospho-, sulfo-, and glyco-peptides such as RRLIEDAEY $\left(\mathrm{H}_{2} \mathrm{PO}_{4}\right)$ AARG from tyrosine kinase peptide, FFKNIVTPRT $\left(\mathrm{H}_{2} \mathrm{PO}_{4}\right)$ PPPSQGK, RDY $\left(\mathrm{SO}_{3}\right)$ TGWLDF and EAISPPDAAS(GalNAc)AAPLR from GalNAc-Ser Erythropoietin (177-131) were obtained from GeneCust Europe. All the peptides were used without any further purification. All the peptide samples were prepared at $2 \mu \mathrm{M}$ concentration in 50/49/1 (v/v/v) methanol/water/acetic acid. 


\section{Mass Spectrometry}

All the experiments were performed on a hybrid quadrupole-Orbitrap Q-Exactive ${ }^{\circledR}$ mass spectrometer (Thermo Fisher Scientific, San Jose, CA, USA) equipped with an HESI ion source. Positive polarity was used for all the peptides. All the mass spectra were acquired using a mass range of $200-2000 \mathrm{~m} / \mathrm{z}$ and resolving power of 140000 at $\mathrm{m} / \mathrm{z} 400$. Spray voltage, capillary temperature, and sheath gas flow rate were set to $3.5-4.0 \mathrm{kV}, 320^{\circ} \mathrm{C}$ and $5-10$ respectively. The AGC (Automatic Gain Control) target was set to $5 \times 10^{6}$ and the maximum injection time was set at $250 \mathrm{~ms}$. The isolation width was 1-2 Th. To avoid collisions and CID contamination, the HCD collision energy was set to the minimum $2 \mathrm{eV}$. All the experiments were performed for 3 microscans with averaging for 50 scans.

\section{Photodissociation}

IRMPD experiments were performed with a $50 \mathrm{~W}$ continuous-wave $\mathrm{CO}_{2}$ laser (Model ULR-50, Universal Laser System ${ }^{\circledR}$, Scottsdale, AZ). To compare backbone fragmentation and retaining PTM groups, various nominal laser powers from 10-60\% were used. However, we noticed that $10-30 \%$ laser power is enough to achieve excellent fragmentation and comparable PTM loss and retention events. Although high laser power can provide a significant number of fragment ions, it is difficult to retain the PTM groups. Compared to protein samples, peptides generally required shorter irradiation times from $50 \mathrm{~ms}$ to $500 \mathrm{~ms}$. For the IRMPD experiment, $\mathrm{N}_{2}$ gas pressure in the HCD cell had to be lowered to reduce collisional cooling and obtain fragmentation [64]. For the PTM peptides, the pressure controller was set to $\sim 0.1$ $0.15 \mathrm{MPa}$ to obtain reasonable trapping and good signals.

For the UVPD experiments, which were similar to the previous experiment [41, 63], the fifth harmonic $(\lambda=213 \mathrm{~nm}, \sim 1 \mathrm{~mJ} /$ pulse) of a $20 \mathrm{~Hz}$ BrillantB solid-state Nd:YAG laser (Quantel, Les Ulis, France) was used. In brief, to generate $213 \mathrm{~nm}$ UV light, the fundamental $1064 \mathrm{~nm}$ light is passed through the non-linear crystal to generate the second harmonic at 532 $\mathrm{nm}$. Then the second harmonic is sent through the second crystal where the fourth harmonic at $266 \mathrm{~nm}$ is generated. The remaining fundamental light is then allowed to interact with the fourth harmonic $(266 \mathrm{~nm})$ to produce the fifth harmonic at $213 \mathrm{~nm}$ by sum-frequency generation (SFG). A mechanical shutter (SH05/TSC001, Thorslab) was used to control the 
UV beam in the HCD cell. For PTM peptides, the optimal shutter opening time used here was 50-100 ms (1-2 laser shots), as these peptides require few UV laser shots.

HiLoPD experiments were performed with combined IRMPD and UVPD irradiation in the HCD cell of a hybrid quadrupole-Orbitrap mass spectrometer. The detailed set up was described elsewhere [64]. In brief, the generated fifth harmonic $213 \mathrm{~nm}$ laser beam passes through two dichroic mirrors, lenses, optical mirrors and is then introduced into the HCD cell. In addition, the IR beam is directed at the HCD cell using gold mirrors and a half-moon (Dshaped) mirror. The IR beam is gated on an external TTL signal. To combine the irradiating $\mathrm{UV}$ and IR beams, a $\mathrm{BaF}_{2}$ window (wavelength range 0.2-12 $\mu \mathrm{m}, \varnothing 25.4 \mathrm{~mm}$, thickness 5 $\mathrm{mm})$ is placed at the rear of the HCD cell. This window can transmit both IR $(10.6 \mu \mathrm{m})$ and UV $(213 \mathrm{~nm})$ beams with an efficiency of 90 and $85 \%$, respectively. Coupling schemes between IR and UV are implemented by simultaneous irradiation of the $\mathrm{CO}_{2}$ laser (50-200 $\mathrm{ms}$ ) with $10-30 \%$ of nominal laser power and 1-2 shots of UV laser.

\section{Data Analysis}

Manual interpretation of the IRMPD, UVPD and HiLoPD data was performed with the assistance of Protein Prospector V5.14.4. (http://prospector.ucsf.edu/prospector/mshome.htm). All the major ion types (a, a+1, a+2, b-1, $\mathrm{b}, \mathrm{b}+1, \mathrm{~b}+2, \mathrm{c}-1, \mathrm{c}, \mathrm{c}+1, \mathrm{x}-1, \mathrm{x}, \mathrm{x}+1, \mathrm{x}+2, \mathrm{y}, \mathrm{y}-1, \mathrm{y}-2, \mathrm{z}-1, \mathrm{z}, \mathrm{z}+1)$ were considered. To identify PTM loss, the exact masses of the labile groups were subtracted from the precursor and fragment ions and a mass list was created in Excel manually. These values were then searched throughout the spectra. $\mathrm{H}_{2} \mathrm{O}$ and $\mathrm{NH}_{3}$ losses from the fragment ions were also considered.

For the PTM loss and retention assessments, the position of the PTM sites relative to the $\mathrm{N}$ - and C-terminal ions of $\mathrm{a} / \mathrm{b} / \mathrm{c}$ and $\mathrm{x} / \mathrm{y} / \mathrm{z}$, respectively, were considered (Scheme 1). Only fragment ions that contained the modified amino acid were taken into account. The losses of similar groups (such as $\mathrm{H}_{3} \mathrm{PO}_{4}$ and $\mathrm{HPO}_{3}$ ) from the same fragment ion were counted as a 'one loss' event. For instance, if both $\mathrm{H}_{3} \mathrm{PO}_{4}$ and $\mathrm{HPO}_{3}$ were lost from the $\mathrm{y}_{5}$ ion, this was counted as a 'one loss' event and not 'two losses'. In addition, the detection of several y-1, y, y+1 or a, $\mathrm{a}+2$ ions from the same backbone position was counted as a 'one retain' event rather than several events. PTM retention specificity was calculated by the following equation: 


$$
\% \text { Retain }=\frac{\sum \text { number of retained PTMs detected }}{\sum \begin{array}{c}
\text { number of PTM losses detected }+\sum \text { number ofretained PTMs detected } \\
\times 100
\end{array}}
$$

\section{Results and Discussion}

IRMPD, UVPD and HILOPD on RRLIEDAEY $\left(\mathrm{H}_{2} \mathrm{PO}_{4}\right) A A R G$

The IRMPD, UVPD and HiLoPD photodissociation spectra of the triply-protonated $[\mathrm{M}+3 \mathrm{H}]^{3+}\left(\mathrm{m} / z\right.$ 533.9346) of peptide RRLIEDAEY $\left(\mathrm{H}_{2} \mathrm{PO}_{4}\right) \mathrm{AARG}$ are presented in Figure 1. Theoretical $\mathrm{m} / \mathrm{z}$, observed $\mathrm{m} / \mathrm{z}$ and assignments for fragment ions detected in the IRMPD, UVPD and HiLoPD experiments on this peptide are summarized in Table S1. The abundance of fragment ions, excluding phosphate losses, in all three methods is compared in Figure 2a.

Since the stretching of the $\mathrm{P}-\mathrm{O}$ bond $\left(9.6-11 \mu \mathrm{m}\right.$ or $\left.1042-909 \mathrm{~cm}^{-1}\right)$ is in resonance with the $10.6 \mu \mathrm{m}$ wavelength, the phosphate group can stimulate chromophore-driven efficient dissociation [65]. The IRMPD spectrum provided a good overall sequence coverage of $75 \%$, including sequence information in the low $\mathrm{m} / \mathrm{z}$ region. IRMPD showed similar sequence coverage with $\mathrm{N}$ - terminal ions and $\mathrm{C}$-terminal ions (66\%). The neural losses of 98.0118 Da and 79.9986 Da, which corresponded to the elimination of $\mathrm{H}_{3} \mathrm{PO}_{4}$ and $\mathrm{HPO}_{3}$ groups, were observed from the precursor ions at $\mathrm{m} / \mathrm{z} 501.2637$ and 507.2681, respectively. The neutral loss of $\mathrm{H}_{2} \mathrm{O}$ was detected at $\mathrm{m} / z$ 527.9238. In addition, IRMPD exhibited substantial backbone fragmentation (excluding phosphate losses) producing $30 \mathrm{~b}$ ions and 13 y ions (Figure 2a). Regarding site-specific PTM losses, 5 were detected from $\mathrm{y}_{\mathrm{n}}$ ions ( $\left.\mathrm{n}=5-9\right)$ while only 2 were identified from $b_{n}$ ions $(n=9,10)$ (Table 1). However, phosphate groups were retained in $4 y_{n}$ ions $(n=5,6,7,8)$. The overall phosphate retention efficiency in IRMPD was $36.4 \%$.

The UVPD experiment on the +3 ion of this peptide allowed the detection of a total of 87 fragment ions (excluding phosphate losses) with 1 laser pulse, which is nearly twice the number of fragment ions detected with IRMPD (Figure 2a and Table S1). The neutral loss peaks at $\mathrm{m} / \mathrm{z} 527.9256,506.9291$ and 501.2650 correspond to the elimination of $\mathrm{H}_{2} \mathrm{O}, \mathrm{HPO}_{3}$ and $\mathrm{H}_{3} \mathrm{PO}_{4}$ from the precursor ion $[\mathrm{M}+3 \mathrm{H}]^{3+}$. The neutral loss of $\mathrm{CH}_{3} \mathrm{CH}_{2}$ noticed at $m / z$ 524.2445 , represents the side chain of Ile [66]. The peak at $\mathrm{m} / \mathrm{z} 498.5760$ corresponds to the loss of $\mathrm{O}=\mathrm{C}_{6} \mathrm{H}_{4}=\mathrm{CH}_{2}(106.0836 \mathrm{Da})$ from tyrosine [67]. However, in comparison to IRMPD only $14 \mathrm{~b}$ ions were identified in UVPD. Besides the traditional $\mathrm{a} / \mathrm{x}, \mathrm{y}$ and $\mathrm{c} / \mathrm{z}$ ions, $\mathrm{a}+1 / \mathrm{x}+1$, 
$\mathrm{x}+2, \mathrm{y}-1, \mathrm{y}-2, \mathrm{c}-1$, and $\mathrm{c}+1$ ions of this peptide were also detected. Despite the absence of a proline residue, we observed $\mathrm{y}-1$ and $\mathrm{y}-2$ ions from the secondary detachment of the $\mathrm{x}+1$ radical $[38,18]$. The UVPD spectrum provided $83 \%$ overall sequence coverage, with a significant number of fragment ions. However, the same sequence coverage (66\%) was observed with $\mathrm{N}$ - and C-terminal ions.

For UVPD, the neutral losses of $\mathrm{H}_{3} \mathrm{PO} 4$ and $\mathrm{HPO}_{3}$ groups from the fragment ions were observed from $y_{n}$ ions at positions $n=5-9$. Only two such losses were identified for $z_{n}$ ions $(\mathrm{n}=5,7)$. Surprisingly, no such phosphate loss was detected for $\mathrm{a}, \mathrm{b}, \mathrm{c}$ or $\mathrm{x}$ ions. A significant number of preserved phosphate groups were observed for $x_{n}(n=5,6,7), y_{n}$ $(n=5,6,7,8), z_{n}(n=5,6)$ and $a_{n}(n=9)$ ions (Table 1). An overall phosphate retention efficiency of $58.8 \%$ was obtained for UVPD.

HiLoPD on the same peptide produced a wider range of fragmentation types, a, b, c, x, $\mathrm{y}$, and $\mathrm{z}$, owing to its high and low activation channels combining UV and IR photodissociation. While UVPD and HiLoPD had the same sequence coverages (83\%), HiLoPD presented a diverse array of fragment ions from the $\mathrm{N}$ and C-terminals. "UV-type" fragment ions (i.e. a/c and $\mathrm{x} / \mathrm{z}$ ) allowed increasing the sequence coverage in HiLoPD compared to IRMPD. A significant number of $b$ ions (31 fragments) were identified in HiLoPD, similar to IRMPD, whereas many of them were absent in UVPD (Figure 2a). However, compared to UVPD, the number of $\mathrm{a} / \mathrm{x}$ ions was lower in HiLoPD. In addition to the traditional ion types, the spectrum also contained highly abundant ions corresponding to neutral losses of water and ammonia from the fragment ions (Table S1). As with UVPD, phosphate losses were observed for $y_{n}(n=5-9)$ and $z_{n}(n=5,7)$ ions (Table 1). Interestingly, it appeared that the loss of $\mathrm{HPO}_{3}$ from y ions was more frequent in HiLoPD and UVPD compared to IRMPD. In general, the activation of phospho-peptide molecular ion by collision induced the cleavage of the $\mathrm{C}-\mathrm{O}-\mathrm{P}$ ester bridge. If the cleavage of $\mathrm{C}-\mathrm{O}$ bond occurred with hydrogen transfer, this led to phosphoric acid $\left(\mathrm{H}_{3} \mathrm{PO}_{4}\right)$ loss, whereas breaking the $\mathrm{O}-\mathrm{P}$ bond promoted the loss of the $\mathrm{HPO}_{3}$ group. In the collision activation of tyrosine phosphorylated peptide, neutral loss of the $\mathrm{HPO}_{3}(79.9657 \mathrm{Da})$ group is usually observed [69] and the loss of the $\mathrm{H}_{3} \mathrm{PO}_{4}$ group is less likely to occur, since the bond dissociation energy of a $\mathrm{C}-\mathrm{O}$ bond adjacent to an aromatic ring is quite high compared to that of a $\mathrm{P}-\mathrm{O}$ bond and the second aromatic group does not promote E2-elimination or $\mathrm{S}_{\mathrm{N}} 2$-neighbouring group participation reaction [70]. Previous studies reported that the $\mathrm{H}_{3} \mathrm{PO}_{4}$ group can be removed from phosphorylated tyrosine through the concurrent or sequential loss of $\mathrm{HPO}_{3}$ from the tyrosine 
residue and of $\mathrm{H}_{2} \mathrm{O}$ from elsewhere in the peptide [71, 72]. Moreover, $7 \mathrm{x}$ and $\mathrm{y}$ ions, still containing the phosphate groups were also detected (Table 1). The overall phosphate retention efficiency in HiLoPD was $50.0 \%$.

Although significant losses of phosphate groups from the product ions are not desirable, some of these losses along with high sequence coverage can certainly confirm the phosphate location on a phospho-peptide. In IRMPD, the elimination of the $\mathrm{H}_{3} \mathrm{PO}_{4}$ group was identified from $b_{9-10}$ as well as from y $5-9$ ions (Table 1). In UVPD and HiLoPD, the neutral losses of $\mathrm{H}_{3} \mathrm{PO} 4$ and $\mathrm{HPO}_{3}$ groups were observed only from $\mathrm{y}_{5-9}, \mathrm{z}_{5}$ and $\mathrm{z}_{7}$ fragment ions. As evidenced by these results, no phosphate loss was detected from $\mathrm{y}_{1-4}$ and $\mathrm{b}_{1-8}$ ions, confirming that the phosphate group was attached to the tyrosine at position 9 from the N-terminal.

\section{IRMPD, UVPD and HILOPD on FFKNIVTPRT $\left(\mathrm{H}_{2} \mathrm{PO}_{4}\right)$ PPPSQGK}

The IRMPD, UVPD and HiLoPD photodissociation spectra of the triply-protonated $[\mathrm{M}+3 \mathrm{H}]^{3+}\left(\mathrm{m} / z\right.$ 665.3544) of peptide FFKNIVTPRT $\left(\mathrm{H}_{2} \mathrm{PO}_{4}\right)$ PPPSQGK is presented in Figure 3. Theoretical $\mathrm{m} / \mathrm{z}$, observed $\mathrm{m} / \mathrm{z}$ and assignments for fragment ions detected in IRMPD, UVPD and HiLoPD experiments on this peptide are summarized in Table S2. Losses of $\mathrm{HPO}_{3}$ and $\mathrm{H}_{3} \mathrm{PO}_{4}$ groups from the precursor ion were detected at $m / z 638.6534$ and 632.6923, respectively. Neutral losses of water and ammonia were also observed in these spectra.

The abundance of fragment ions excluding phosphate losses in all three methods is compared in Figure 2b.The IRMPD, UVPD and HiLoPD spectra provided excellent sequence coverage (94\%-100\%) and with a substantial number of fragment ions. Nearly equal numbers of b (27) and y (25) ions were detected in IRMPD (Figure 2b). In UVPD, a significant number of fragment ions were observed compared to IRMPD and HiLoPD.

With IRMPD, the losses of $\mathrm{H}_{3} \mathrm{PO}_{4} / \mathrm{HPO}_{3}$ groups were detected from $\mathrm{b}_{10-12}, \mathrm{~b}_{15}$ and $\mathrm{b}_{16}$ ions as well as from $\mathrm{y}_{8-12}, \mathrm{y}_{14}$ and $\mathrm{y}_{16}$ ions (Table 2). However, $\mathrm{b}_{\mathrm{n}}(\mathrm{n}=10,12-16)$ and $\mathrm{y}_{\mathrm{n}}(\mathrm{n}=8$ 14) fragment ions retained the phosphate groups. The overall phosphate retention efficiency achieved with IRMPD is 52\%. In UVPD, significant numbers (42) of fragment ions such as $a_{n}$ $(n=10-16), b_{n}(n=10-16), c_{n}(n=13-16), x_{n}(n=8-16), y_{n}(n=8-16)$ and $z_{n}(n=11-16)$ retain the phosphate groups (Table 2). However, phosphate losses occurred only from 29 fragment ions. The phosphate retention efficiency attained in UVPD was higher (59\%) than that for IRMPD (52\%) and HiLoPD (52\%). For this phospho-threonine peptide, no phosphate loss 


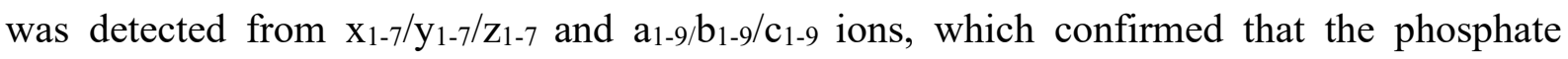
group is attached to the threonine at position 10 from the N-terminal.

\section{IRMPD, UVPD and HiLoPD on RDY(SOH $) T G W L D F$}

The IRMPD, UVPD and HiLoPD photodissociation spectra of the doubly-protonated $[\mathrm{M}+2 \mathrm{H}]^{2+}\left(m / z\right.$ 626.7492) of peptide $\mathrm{RDY}\left(\mathrm{SO}_{3}\right) \mathrm{TGWLDF}$ are presented in Figure 4. The observed $\mathrm{m} / \mathrm{z}$ and assignments of fragment ions of this peptide are summarized in Table S3. The numbers of fragment ions (excluding sulfonate loss) detected by IRMPD, UVPD and HiLoPD are summarized in Figure 2c. Singly and doubly protonated precursor ions provided nearly the same fragment ions in UVPD; however, the singly protonated ion was not stable and was difficult to isolate prior to MS/MS activation in IRMPD and HiLoPD methods. Similar events were also witnessed in a previous study [47]. In contrast, the doublyprotonated ion of this peptide was easier to analyze with all three methods. Moreover, earlier studies reported that higher charge states can increase the sulfonate retention [39]. In all cases, the neutral loss of $\mathrm{SO}_{3}(79.9573 \mathrm{Da})$ was observed at $\mathrm{m} / z 1172.5388$ from the $[\mathrm{M}+\mathrm{H}]^{+}$ions and at $\mathrm{m} / \mathrm{z} 586.7710$ from the precursor ion, respectively. Moreover, the sequential loss of $\mathrm{SO}_{3}$ and $\mathrm{H}_{2} \mathrm{O}$ was detected at $\mathrm{m} / z 577.7677$ from the precursor ion.

The vibrational frequencies of $\mathrm{C}-\mathrm{O}\left(\mathrm{SO}_{3}\right)$ and symmetrical $\mathrm{O}=\mathrm{S}=\mathrm{O}$ were in the range 9.4-10 $\mu \mathrm{m}$ [73] which is very close to the wavelength of the $\mathrm{CO}_{2}$ laser $(10.6 \mu \mathrm{m})$. The IRMPD spectrum provided $87 \%$ sequence coverage and was dominated by series of y-ions, as well as minor contributions from b-ions (Figure 2c). Although more fragment ions were generated from the $\mathrm{C}$-terminal, higher sequence coverage was observed for the $\mathrm{N}$-terminal $(87.5 \%)$ compared to the C-terminal (62.5\%). Most of the y ions were formed close to the aspartic acid at position 2. Previous collision induced dissociation (CID) studies have shown that acidic residues near the C-terminus may promote the formation of y ions in sulfonated peptides [74]. Some y ions in IRMPD eliminated a molecule of water $(18 \mathrm{Da})$ in secondary fragmentation. Interestingly, the loss of $\mathrm{SO}_{3}$ was seen predominantly from $\mathrm{b}_{3-8}$ ions but no such loss was detected from y ions (Table 3), probably due to the location of the PTM close to the Nterminal.

UVPD and HiLoPD of the doubly protonated precursor ion provided $100 \%$ sequence coverage with $\mathrm{a} / \mathrm{x}, \mathrm{b} / \mathrm{y}$ and $\mathrm{c} / \mathrm{z}$ ions. 20 and 28 fragment ions (excluding $\mathrm{SO}_{3}$ loss) were detected in UVPD and HiLoPD, respectively. In addition to the typical fragment ions types, the UVPD and HiLoPD spectra also showed abundant ions corresponding to consecutive 
neutral losses of water and ammonia. The losses of 171.0099 and $129.0141 \mathrm{Da}$ from the precursor ions corresponded to the removal of the related ion of tryptophan at $\mathrm{m} / \mathrm{z} 541.2400$ and the immonium ion of arginine at $m / z$ 562.2380, respectively (Table S3). Hydrogen deficient and hydrogen rich fragment ions were prevalent with UVPD and HiLoPD. The loss of $\mathrm{SO}_{3}$ from the backbone $\mathrm{a} / \mathrm{b} / \mathrm{c}$ fragment ions in UVPD and HiLoPD could be observed (Table 3). Only few a and c ions still containing the $\mathrm{SO}_{3}$ group were detected. As with IRMPD, the overall $\mathrm{SO}_{3}$ retention efficiency obtained by these two methods was very poor $(12.5 \%)$.

In addition to sequence coverage and retention efficiency, the actual site of sulfation had to be pinpointed. Although the CID method has routinely been utilized to confirm the presence of sulfo groups detecting the neural loss of $\mathrm{SO}_{3}$ from the precursor ion, backbone fragment ions are required to confirm the position [47]. In IRMPD, UVPD and HiLoPD, no $\mathrm{SO}_{3}$ loss was detected from $\mathrm{a}_{1-2} / \mathrm{b}_{1-2} / \mathrm{c}_{1-2}$ and this loss was noticed only from $\mathrm{a}_{3} / \mathrm{b}_{3} / \mathrm{c}_{3}$ and onward. In addition, no loss of $\mathrm{SO}_{3}$ was witnessed from $\mathrm{x}_{1-6} / \mathrm{y}_{1-6} / \mathrm{z}_{1-6}$ ions and such losses began to occur only from $\mathrm{y}_{7}$ and $\mathrm{x}_{8} / \mathrm{z}_{8}$ ions, which confirmed the presence of the $\mathrm{SO}_{3}$ group on tyrosine at position 3 from the N-terminal.

\section{IRMPD, UVPD and HiLoPD on EAISPPDAAS (GalNAc) AAPLR}

High throughput and residue-specific investigation of the O-glycosylation is challenging since the O-glycan core structure is very heterogeneous compared to that of $\mathrm{N}$ glycan and there is no straightforward protein sequence available for O-glycan $[5,75,76]$. In a given protein, O-glycan can be found with several serine/threonine residues. The collision induced dissociation (CID) technique is routinely used for deducing glycan composition; however, determining the exact position of glycosylation and the peptide sequence is difficult to achieve. Although IRMPD provides quite similar fragment ions to CID, a previous study demonstrated that a low photon energy based method can detect informative side chain losses from non-glycosylated serine and threonine residues, which indirectly implicates glycan attachment sites [75].

The IRMPD photodissociation spectrum obtained for the triply-protonated $[\mathrm{M}+3 \mathrm{H}]^{3+}$ $(\mathrm{m} / z$ 556.9529) of peptide EAISPPDAAS(GalNAc)AAPLR is presented in Figure 5. Theoretical and observed $\mathrm{m} / \mathrm{z}$ values of fragment ions of this peptide are summarized in Table S4. The abundance of fragment ions excluding glycan losses in all three methods is compared in Figure 2d. The sequence coverage obtained by IRMPD is $86 \%$. The neutral losses of 
GalNAc (221.0999 Da) and GalNAc- $\mathrm{H}_{2} \mathrm{O}$ (203.0899 Da) from the precursor ion were observed at $\mathrm{m} / \mathrm{z} 483.2556$ and 489.2591, respectively. For all the methods, the sequential losses of GalNAc and $\mathrm{H}_{2} \mathrm{O}$ were observed specifically from positions $b_{10}-b_{12}$. In IRMPD, nearly equal numbers of $\mathrm{b}$ and $\mathrm{y}$ ions could be seen (Figure 2d). The neutral losses of GalNAc and GalNAc- $\mathrm{H}_{2} \mathrm{O}$ from $\mathrm{b}_{10-12}$ ions are apparent whereas for $\mathrm{y}_{\mathrm{n}}$ ions these occurred from $n=7,8,10$, and 12 (Table 4). No such neutral losses were observed for $b_{1-9}$ and $y_{1-5}$, which unambiguously confirmed that the GalNAc group is attached to serine at position 10 from the N-terminal. Some GalNAc groups were also preserved in $\mathrm{y} / \mathrm{b}$ ions (Table 4). Overall, IRMPD showed 41.6\% PTM retention efficiency, which was better than the sulfopeptide.

The UVPD spectrum provided a wealth of fragment ions with a sequence coverage of $86 \%$. A significant number of $\mathrm{a} / \mathrm{x}$ and $\mathrm{b} / \mathrm{y}$ ions retaining the GalNAc group were detected. Compared to IRMPD (23 ions), the UVPD spectrum provided more fragment ions (63 ions) (Figure 2d). In addition, some $\mathrm{c}$ and $\mathrm{z}$ ions were also observed. Moreover, the neutral losses of GalNAc (221.0999Da) and GalNAc- $\mathrm{H}_{2} \mathrm{O}$ (203.0899 Da) groups were observed from all the series of ions (Table S4). More losses were detected from $\mathrm{y} / \mathrm{b}$ ions compared to other fragment ions. However, several $\mathrm{a} / \mathrm{x}, \mathrm{b} / \mathrm{y}$ and $\mathrm{z}$ fragment ions containing the PTM were detected (Table 4). The overall PTM retention efficiency was $46.6 \%$.

In HiLoPD, a significant number of $\mathrm{a} / \mathrm{x}, \mathrm{b} / \mathrm{y}$ and $\mathrm{c} / \mathrm{z}$ ions were identified with similar sequence coverage ( $86 \%$ ) from the $\mathrm{N}$ - and $\mathrm{C}$-terminals. The number of $\mathrm{b}$ ions detected in HiLoPD was higher than in UVPD and IRMPD. As in our previous studies, the number of a ions was lower in comparison to UVPD, possibly due to the secondary fragmentation of these ions [64]. Interestingly, very few x ions were generated in HiLoPD or in UVPD. Compared to UVPD, the neutral losses of GalNAc and GalNAC- $\mathrm{H}_{2} \mathrm{O}$ groups were significantly reduced in HiLoPD. Such losses were only observed for b/y and c ions (Table 4). All a and z ions retained glycan groups. As with UVPD and IRMPD, neutral losses started to occur from positions 10 and 7 from the $\mathrm{N}$ - and $\mathrm{C}$-terminals, respectively, which confirms the position of the glycan group (in serine at position 10 from the $\mathrm{N}$-terminal) in this peptide. The retention efficiency of GalNAc in HiLoPD was 55.0\%, which was the highest efficiency compared to IRMPD (41.6\%) and UVPD (46.6\%).

\section{Conclusion}


In this work, we reported the use of IRMPD, UVPD and HiLoPD to characterize phospho-, sulfo- and glyco-peptides in the gas phase. These results showed the proof-ofprincipal of $213 \mathrm{~nm}$ UVPD and HiLoPD methods for PTM characterization. Compared to a whole protein, the characterization of these PTM peptides requires lower $\mathrm{CO}_{2}$ laser power and fewer UV laser shots. Controlled and tunable parameters can improve the performance of these techniques. The IRMPD results demonstrated that sufficient backbone fragmentation and sequence coverage can be obtained. The IRMPD sequence coverage for phosphotyrosine, phospho-threonine, sulfo- and glyco-peptides was 75, 94\%, 87 and 86\%, respectively. The exact location of the PTM groups in a peptide can be pinpointed. However, fragment-specific and overall PTM retention efficiency in IRMPD was somewhat reduced for all peptides. Compared to phospho- and glyco-peptides, the $\mathrm{SO}_{3}$ group was very prompt to dissociate in IRMPD, which may have been due to the low bond dissociation energy associated with the $\mathrm{O}-\mathrm{S}$ bond or strong absorption of $10.64 \mu \mathrm{m}$ IR photons by the $\mathrm{SO}_{3}$ group. This is the first study of $213 \mathrm{~nm}$ UVPD and HiLoPD used to characterize different PTM peptides. UVPD and HiLoPD gave excellent sequence coverage of 83, 100, 100 and 86\%, for phospho-tyrosine, phospho-threonine, sulfo- and glyco-peptides. PTM retention efficiencies were better than in IRMPD (up to 59\% for the phospho-peptides). Photodissociation at 213 nm UVPD and HiLoPD on peptide cations offers several promising benefits including: i) the production of more arrays of fragment ions with excellent sequence coverage; ii) the identification of the exact PTM position; iii) balanced PTM loss and retention events; and iv) no widespread side-chain losses. Our first set of results show that UVPD and HiLoPD prove to be promising methods for characterizing phospho- and glyco-proteomics.

\section{Acknowledgments}

The research leading to these results has received funding from the European Research Council under the European Union's Seventh Framework Program (FP7/2007-2013 Grant agreement No. 320659). They also thank Dr. Steven Daly (ILM, CNRS et Université Lyon1, France) for improving the English of this manuscript. 


\section{References}

1. Mann, M., Jensen, O.N.: Proteomic analysis of post-translational modifications. Nat. Biotechnol. 21, 255-261 (2003). doi:doi:10.1038/nbt0303-255

2. Zhao, Y., Jensen, O.N.: Modification-specific proteomics: Strategies for characterization of post-translational modifications using enrichment techniques. Proteomics. 9, 4632-4641 (2009). doi:10.1002/pmic.200900398

3. Macek, B., Mann, M., Olsen, J. V: Global and Site-Specific Quantitative Phosphoproteomics: Principles and Applications. Annu. Rev. Pharmacol. Toxicol. 49, 199-221 (2009). doi:10.1146/annurev.pharmtox.011008.145606

4. Önnerfjord, P., Heathfield, T.F., Heinegård, D.: Identification of Tyrosine Sulfation in Extracellular Leucine-rich Repeat Proteins Using Mass Spectrometry. J. Biol. Chem. . 279 , 26-33 (2004). doi:10.1074/jbc.M308689200

5. Christiansen, M.N., Kolarich, D., Nevalainen, H., Packer, N.H., Jensen, P.H.: Challenges of determining o-glycopeptide heterogeneity: A fungal glucanase model system. Anal. Chem. 82, 3500-3509 (2010). doi:10.1021/ac901717n

6. Cohen, P.: The origins of protein phosphorylation. Nat Cell Biol. 4, E127-E130 (2002). doi:10.1038/ncb0502-e127

7. Ubersax, J.A., Ferrell Jr, J.E.: Mechanisms of specificity in protein phosphorylation. Nat Rev Mol Cell Biol. 8, 530-541 (2007). doi:10.1038/nrm2203

8. Pearce, L.R., Komander, D., Alessi, D.R.: The nuts and bolts of AGC protein kinases. Nat Rev Mol Cell Biol. 11, 9-22 (2010). doi:10.1038/nrm2822

9. Bettelheim, F.R.: Tyrosine-O-Sulfate in a Peptide from Fibrinogen. J. Am. Chem. Soc. 76, 2838-2839 (1954). doi:10.1021/ja01639a073

10. Moore, K.L.: Protein tyrosine sulfation: A critical posttranslation modification in plants and animals. Proc. Natl. Acad. Sci. . 106 , 14741-14742 (2009). doi:10.1073/pnas.0908376106

11. Yu, Y., Hoffhines, A.J., Moore, K.L., Leary, J.A.: Determination of the sites of tyrosine O-sulfation in peptides and proteins. Nat Meth. 4, 583-588 (2007). 
doi:10.1038/nmeth1056

12. Steen, P. Van den, Rudd, P.M., Dwek, R.A., Opdenakker, G.: Concepts and Principles of O-Linked Glycosylation. Crit. Rev. Biochem. Mol. Biol. 33, 151-208 (1998). doi:10.1080/10409239891204198

13. Gill, D.J., Clausen, H., Bard, F.: Location, location, location: new insights into OGalNAc protein glycosylation. Trends Cell Biol. 21, 149-158 (2017). doi:10.1016/j.tcb.2010.11.004

14. Kreisman, L.S.C., Cobb, B.A.: Infection, inflammation and host carbohydrates: A Glyco-Evasion Hypothesis. Glycobiology. 22, 1019-1030 (2012). doi:10.1093/glycob/cws070

15. Pinho, S.S., Reis, C.A.: Glycosylation in cancer: mechanisms and clinical implications. Nat Rev Cancer. 15, 540-555 (2015). doi:10.1038/nrc3982

16. Freeze, H.H., Eklund, E.A., Ng, B.G., Patterson, M.C.: Neurological Aspects of Human Glycosylation Disorders. Annu. Rev. Neurosci. 38, 105-125 (2015). doi:10.1146/annurev-neuro-071714-034019

17. Schedin-Weiss, S., Winblad, B., Tjernberg, L.O.: The role of protein glycosylation in Alzheimer disease. FEBS J. 281, 46-62 (2014). doi:10.1111/febs.12590

18. Hwang, H., Zhang, J., Chung, K.A., Leverenz, J.B., Zabetian, C.P., Peskind, E.R., Jankovic, J., Su, Z., Hancock, A.M., Pan, C., Montine, T.J., Pan, S., Nutt, J., Albin, R., Gearing, M., Beyer, R.P., Shi, M., Zhang, J.: Glycoproteomics in neurodegenerative diseases. Mass Spectrom. Rev. 29, 79-125 (2010). doi:10.1002/mas.20221

19. Pan, S., Chen, R., Aebersold, R., Brentnall, T.A.: Mass Spectrometry Based Glycoproteomics-From a Proteomics Perspective. Mol. Cell. Proteomics . 10 , (2011). doi:10.1074/mcp.R110.003251

20. Masselon, C., Anderson, G.A., Harkewicz, R., Bruce, J.E., Pasa-Tolic, L., Smith, R.D.: Accurate mass multiplexed tandem mass spectrometry for high-throughput polypeptide identification from mixtures. Anal. Chem. 72, 1918-1924 (2000). doi:10.1021/ac991133+

21. Pandey, A., Mann, M.: Proteomics to study genes and genomes. Nature. 405, 837-846 (2000). doi:10.1038/35015709 
22. Crowe, M.C., Brodbelt, J.S.: Infrared multiphoton dissociation (IRMPD) and collisionally activated dissociationof peptides in a quadrupole ion trapwith selective IRMPD of phosphopeptides. J. Am. Soc. Mass Spectrom. 15, 1581-1592 (2004). doi:10.1016/j.jasms.2004.07.016

23. Zolodz, M.D., Wood, K. V: Detection of tyrosine phosphorylated peptides via skimmer collision-induced dissociation/ion trap mass spectrometry. J. Mass Spectrom. 38, 257264 (2003). doi:10.1002/jms.435

24. Affolter, M., Watts, J.D., Krebs, D.L., Aebersold, R.: Evaluation of Two-Dimensional Phosphopeptide Maps by Electrospray Ionization Mass Spectrometry of Recovered Peptides. Anal. Biochem. 223, 74-81 (1994). doi:10.1006/abio.1994.1549

25. Cook, S.L., Jackson, G.P.: Metastable Atom-Activated Dissociation Mass Spectrometry of Phosphorylated and Sulfonated Peptides in Negative Ion Mode. J. Am. Soc. Mass Spectrom. 22, 1088-1099 (2011). doi:10.1007/s13361-011-0123-y

26. Edelson-Averbukh, M., Shevchenko, A., Pipkorn, R., Lehmann, W.D.: Discrimination Between Peptide O-Sulfo- and O-Phosphotyrosine Residues by Negative Ion Mode Electrospray Tandem Mass Spectrometry. J. Am. Soc. Mass Spectrom. 22, 2256-2268 (2011). doi:10.1007/s13361-011-0248-Z

27. Cotham, V.C., McGee, W.M., Brodbelt, J.S.: Modulation of phosphopeptide fragmentation via dual spray ion/ion reactions using a sulfonate-incorporating reagent. Anal. Chem. 88, 8158-8165 (2016). doi:10.1021/acs.analchem.6b01901

28. Zubarev, R.A., Kelleher, N.L., McLafferty, F.W.: Electron capture dissociation of multiply charged protein cations. A nonergodic process. J. Am. Chem. Soc. 120, 32653266 (1998). doi:10.1021/ja973478k

29. Syka, J.E.P., Coon, J.J., Schroeder, M.J., Shabanowitz, J., Hunt, D.F.: Peptide and protein sequence analysis by electron transfer dissociation mass spectrometry. Pro. Natl. Acad. Sci. USA. 101, 9528-9533 (2004). doi:10.1073/pnas.0402700101

30. Zhurov, K.O., Fornelli, L., Wodrich, M.D., Laskay, U.A., Tsybin, Y.O.: Principles of electron capture and transfer dissociation mass spectrometry applied to peptide and protein structure analysis. Chem. Soc. Rev. 42, 5014-5030 (2013).

doi:10.1039/C3CS35477F 
31. Coon, J.J.: Collision or Electron? Protein Sequence Analysis on the 21st Century. Anal. Chem. 81, 3208-3215 (2009). doi:10.1021/ac802330b

32. Shi, S.D.H., Hemling, M.E., Carr, S.A., Horn, D.M., Lindh, I., McLafferty, F.W.: Phosphopeptide/Phosphoprotein Mapping by Electron Capture Dissociation Mass Spectrometry. Anal. Chem. 73, 19-22 (2000). doi:10.1021/ac000703z

33. Good, D.M., Wirtala, M., McAlister, G.C., Coon, J.J.: Performance Characteristics of Electron Transfer Dissociation Mass Spectrometry. Mol. Cell. Proteomics. 6, 19421951 (2007). doi:10.1074/mcp.M700073-MCP200

34. Frese, C.K., Altelaar, A.F.M., Hennrich, M.L., Nolting, D., Zeller, M., Griep-Raming, J., Heck, A.J.R., Mohammed, S.: Improved Peptide Identification by Targeted Fragmentation Using CID, HCD and ETD on an LTQ-Orbitrap Velos. J. Proteome Res. 10, 2377-2388 (2011). doi:10.1021/pr1011729

35. Asakawa, D., Takeuchi, T., Yamashita, A., Wada, Y.: Influence of Metal-Peptide Complexation on Fragmentation and Inter-Fragment Hydrogen Migration in Electron Transfer Dissociation. J. Am. Soc. Mass Spectrom. 25, 1029-1039 (2014). doi:10.1007/s13361-014-0855-6

36. Asakawa, D., Osaka, I.: High-Confidence Sequencing of Phosphopeptides by Electron Transfer Dissociation Mass Spectrometry Using Dinuclear Zinc(II) Complex. Anal. Chem. 88, 12393-12402 (2016). doi:10.1021/acs.analchem.6b03645

37. Loo, J.A., Loo, R.R.O., Light, K.J., Edmonds, C.G., Smith, R.D.: Multiply Charged Negative Ions by Electrospray Ionization of Polypeptides and Proteins. Anal. Chem. 64, 81-88 (1992). doi:10.1021/ac00025a015

38. Huzarska, M., Ugalde, I., Kaplan, D.A., Hartmer, R., Easterling, M.L., Polfer, N.C.: Negative Electron Transfer Dissociation of Deprotonated Phosphopeptide Anions: Choice of Radical Cation Reagent and Competition between Electron and Proton Transfer. Anal. Chem. 82, 2873-2878 (2010). doi:10.1021/ac9028592

39. Hersberger, K.E., Håkansson, K.: Characterization of O -Sulfopeptides by Negative Ion Mode Tandem Mass Spectrometry: Superior Performance of Negative Ion Electron Capture Dissociation. Anal. Chem. 84, 6370-6377 (2012)

40. Madsen, J.A., Xu, H., Robinson, M.R., Horton, A.P., Shaw, J.B., Giles, D.K., Kaoud, 
T.S., Dalby, K.N., Trent, M.S., Brodbelt, J.S.: High-throughput Database Search and Large-scale Negative Polarity Liquid Chromatography-Tandem Mass Spectrometry with Ultraviolet Photodissociation for Complex Proteomic Samples. Mol. Cell. Proteomics. 12, 2604-2614 (2013). doi:10.1074/mcp.O113.028258

41. Halim, M., Girod, M., MacAleese, L., Lemoine, J., Antoine, R., Dugourd, P.: 213 nm Ultraviolet Photodissociation on Peptide Anions: Radical-Directed Fragmentation Patterns. J. Am. Soc. Mass Spctrom. 27, 474-486 (2016). doi:10.1007/s13361-015$1297-5$

42. Riley, N.M., Rush, M.J.P., Rose, C.M., Richards, A.L., Kwiecien, N.W., Bailey, D.J., Hebert, A.S., Westphall, M.S., Coon, J.J.: The Negative Mode Proteome with Activated Ion Negative Electron Transfer Dissociation (AI-NETD). Mol. Cell. Proteomics . 14 , 2644-2660 (2015). doi:10.1074/mcp.M115.049726

43. Riley, N.M., Bern, M., Westphall, M.S., Coon, J.J.: Full-Featured Search Algorithm for Negative Electron-Transfer Dissociation. J. Proteome Res. 15, 2768-2776 (2016). doi:10.1021/acs.jproteome.6b00319

44. Bowie, J.H., Brinkworth, C.S., Dua, S.: Collision-induced fragmentations of the (MH)- parent anions of underivatized peptides: An aid to structure determination and some unusual negative ion cleavages. Mass Spectrom. Rev. 21, 87-107 (2002). doi:10.1002/mas.10022

45. Shaw, J.B., Kaplan, D.A., Brodbelt, J.S.: Activated Ion Negative Electron Transfer Dissociation of Multiply Charged Peptide Anions. Anal. Chem. 85, 4721-4728 (2013). doi:10.1021/ac4005315

46. Kim, T.-Y., Reilly, J.P.: Time-Resolved Observation of Product Ions Generated by 157 nm Photodissociation of Singly Protonated Phosphopeptides. J. Am. Soc. Mass Spectrom. 20, 2334-2341 (2009). doi:10.1016/j.jasms.2009.08.021

47. Robinson, M.R., Moore, K.L., Brodbelt, J.S.: Direct Identification of Tyrosine Sulfation by using Ultraviolet Photodissociation Mass Spectrometry. J. Am. Soc. Mass Spectrom. 25, 1461-1471 (2014). doi:10.1007/s13361-014-0910-3

48. Madsen, J. a., Kaoud, T.S., Dalby, K.N., Brodbelt, J.S.: 193-Nm Photodissociation of Singly and Multiply Charged Peptide Anions for Acidic Proteome Characterization. Proteomics. 11, 1329-1334 (2011). doi:10.1002/pmic.201000565 
49. Fort, K.L., Dyachenko, A., Potel, C.M., Corradini, E., Marino, F., Barendregt, A., Makarov, A.A., Scheltema, R.A., Heck, A.J.R.: Implementation of Ultraviolet Photodissociation on a Benchtop Q Exactive Mass Spectrometer and Its Application to Phosphoproteomics. Anal. Chem. 88, 2303-2310 (2016).

doi:10.1021/acs.analchem.5b04162

50. Robinson, M.R., Taliaferro, J.M., Dalby, K.N., Brodbelt, J.S.: 193 Nm Ultraviolet Photodissociation Mass Spectrometry for Phosphopeptide Characterization in the Positive and Negative Ion Modes. J. Proteome Res. 15, 2739-2748 (2016). doi:10.1021/acs.jproteome.6b00289

51. Lemoine, J., Tabarin, T., Antoine, R., Broyer, M., Dugourd, P.: UV photodissociation of phospho-seryl-containing peptides: Laser stabilization of the phospho-seryl bond with multistage mass spectrometry. Rapid Commun. Mass Spectrom. 20, 507-511 (2006). doi:10.1002/rcm.2333

52. Park, S., Ahn, W.-K., Lee, S., Han, S.Y., Rhee, B.K., Oh, H. Bin: Ultraviolet photodissociation at $266 \mathrm{~nm}$ of phosphorylated peptide cations. Rapid Commun. Mass Spectrom. 23, 3609-3620 (2009). doi:10.1002/rcm.4184

53. Antoine, R., Joly, L., Tabarin, T., Broyer, M., Dugourd, P., Lemoine, J.: Photo-induced formation of radical anion peptides. Electron photodetachment dissociation experiments. Rapid Commun. Mass Spectrom. 21, 265-268 (2007). doi: $10.1002 / \mathrm{rcm} .2810$

54. Madsen, J.A., Kaoud, T.S., Dalby, K.N., Brodbelt, J.S.: 193-nm photodissociation of singly and multiply charged peptide anions for acidic proteome characterization. Proteomics. 11, 1329-1334 (2011). doi:10.1002/pmic.201000565

55. Robinson, M.R., Moore, K.L., Brodbelt, J.S.: Direct identification of tyrosine sulfation by using ultraviolet photodissociation mass spectrometry. J. Am. Soc. Mass Spectrom. 25, 1461-1471 (2014). doi:10.1007/s13361-014-0910-3

56. Crowe, M.C., Brodbelt, J.S.: Infrared multiphoton dissociation (IRMPD) and collisionally activated dissociation of peptides in a quadrupole ion trap with selective IRMPD of phosphopeptides. J. Am. Chem. Soc. 15, 1581-1592 (2004). doi:10.1016/j.jasms.2004.07.016

57. Wilson, J.J., Brodbelt, J.S.: Infrared Multiphoton Dissociation for Enhanced de Novo 
Sequence Interpretation of N-Terminal Sulfonated Peptides in a Quadrupole Ion Trap. Anal. Chem. 78, 6855-6862 (2006). doi:10.1021/ac060760d

58. Pikulski, M., Hargrove, A., Shabbir, S.H., Anslyn, E. V, Brodbelt, J.S.: Sequencing and Characterization of Oligosaccharides Using Infrared Multiphoton Dissociation and Boronic Acid Derivatization in a Quadrupole Ion Trap. J. Am. Soc. Mass Spectrom. 18, 2094-2106 (2007). doi:/10.1016/j.jasms.2007.09.005

59. Li, B., Russell, S.C., Zhang, J., Hedrick, J.L., Lebrilla, C.B.: Structure determination by MALDI-IRMPD mass spectrometry and exoglycosidase digestions of O-linked oligosaccharides from Xenopus borealis egg jelly. Glycobiology. 21, 877-894 (2011). doi:http://dx.doi.org/10.1093/glycob/cwr003

60. Park, Y., Lebrilla, C.B.: Application of Fourier transform ion cyclotron resonance mass spectrometry to oligosaccharides. Mass Spectrom. Rev. 24, 232-264 (2005). doi:10.1002/mas.20010

61. Brodbelt, J.S., Wilson, J.J.: Infrared multiphoton dissociation in quadrupole ion traps. Mass Spectrom. Rev. 28, 390-424 (2009). doi:10.1002/mas.20216

62. Zhou, W., Hakansson, K.: Structural Characterization of Carbohydrates by Fourier Transform Tandem Mass Spectrometry. Curr. Proteomics. 8, 297-308 (2011). doi:10.2174/157016411798220826

63. Girod, M., Sanader, Z., Vojkovic, M., Antoine, R., MacAleese, L., Lemoine, J., Bonacic-Koutecky, V., Dugourd, P.: UV Photodissociation of Proline-containing Peptide Ions: Insights from Molecular Dynamics. J. Am. Soc. Mass Spctrom. 26, 432443 (2014). doi:10.1007/s13361-014-1038-1

64. Halim, M.A., Girod, M., MacAleese, L., Lemoine, J., Antoine, R., Dugourd, P.: Combined Infrared Multiphoton Dissociation with Ultraviolet Photodissociation for Ubiquitin Characterization. J. Am. Soc. Mass Spectrom. 27, 1435-1442 (2016). doi:10.1007/s13361-016-1419-8

65. Flora, J.W., Muddiman, D.C.: Determination of the relative energies of activation for the dissociation of aromatic versus aliphatic phosphopeptides by ESI-FTICR-MS and IRMPD. J. Am. Soc. Mass Spectrom. 15, 121-127 (2004).

doi:10.1016/j.jasms.2003.10.004 
66. Han, H., Xia, Y., McLuckey, S.A.: Ion Trap Collisional Activation of $\mathrm{c}$ and $\mathrm{z} \bullet$ Ions Formed via Gas-Phase Ion/Ion Electron-Transfer Dissociation. J. Proteome Res. 6, 3062-3069 (2007). doi:10.1021/pr070177t

67. Antoine, R., Lemoine, J., Dugourd, P.: Electron Photodetachment Dissociation for Structural Characterization of Synthetic and Bio-Polymer Anions. Mass Spectrom. Rev. 33, 501-522 (2014). doi:10.1002/mas.21402

68. Madsen, J., Cheng, R.R., Kaoud, T.S., Dalby, K., Makarov, D.E., Brodbelt, J.: Chargesite-dependent dissociation of hydrogen-rich radical peptide cations upon vacuum UV photoexcitation. Chem. Eur. J. 18, 5374-5383 (2012). doi:10.1002/chem.201103534

69. DeGnore, J., Qin, J.: Fragmentation of phosphopeptides in an ion trap mass spectrometer. J. Am. Soc. Mass Spectrom. 9, 1175-1188 (1998). doi:10.1016/S10440305(98)00088-9

70. Tholey, A., Reed, J., Lehmann, W.D.: Electrospray tandem mass spectrometric studies of phosphopeptides and phosphopeptide analogues. J Mass Spectrom. 34, 117-123 (1999). doi:3.0.CO;2-V

71. Moyer, S.C., VonSeggern, C.E., Cotter, R.J.: Fragmentation of cationized phosphotyrosine containing peptides by atmospheric pressure MALDI/Ion trap mass spectrometry. J. Am. Soc. Mass Spectrom. 14, 581-592 (2003). doi:10.1016/S10440305(03)00142-9

72. Annan, R.S., Carr, S. a: Phosphopeptide analysis by matrix-assisted laser desorption time-of-flight mass spectrometry. Anal. Chem. 68, 3413-3421 (1996)

73. Paciotti, R., Coletti, C., Re, N., Scuderi, D., Chiavarino, B., Fornarini, S., Crestoni, M.E.: Serine O-sulfation probed by IRMPD spectroscopy. Phys. Chem. Chem. Phys. 17, 25891-25904 (2015). doi:10.1039/C5CP01409C

74. Budnik, B. a., Haselmann, K.F., Zubarev, R. a.: Electron detachment dissociation of peptide di-anions: An electron-hole recombination phenomenon. Chem. Phys. Lett. 342, 299-302 (2001). doi:10.1016/S0009-2614(01)00501-2

75. Seipert, R.R., Dodds, E.D., Lebrilla, C.B.: Exploiting differential dissociation chemistries of O-linked glycopeptide ions for the localization of mucin-type protein glycosylation. J. Proteome Res. 8, 493-501 (2009). doi:10.1021/pr8007072 
76. Zhu, Z., Su, X., Clark, D.F., Go, E.P., Desaire, H.: Characterizing O-Linked glycopeptides by electron transfer dissociation: Fragmentation rules and applications in data analysis. Anal. Chem. 85, 8403-8411 (2013). doi:10.1021/ac401814h 